\title{
Serebral palsi -epidemiyoloji, etiyoloji ve patoloji
}

\author{
Cerebral palsy -epidemiology, etiology and pathology
}

\author{
Yasemin Topçu, Kürşad Aydın
}

Medipol Üniversitesi Tıp Fakültesi, Çocuk Nörolojisi Bilim Dalı, İstanbul

\begin{abstract}
Serebral palsi (SP) kas tonusu, postür ve hareket bozukluğu ile karakterize, ağırlığı değişken, heterojen bir grup klinik sendromdur. SP, gelişmekte olan immatür beyinde çeşitli nedenlerin yol açtığı zedelenmeler sonucu ortaya çıkar. SP'nin genel prevalansı her 1000 canlı doğumda yaklaşık 2'dir. SP prevalansı, term bebeklerle karşılaştırıldığında preterm bebeklerde çok daha yüksektir ve gestasyonel yaş ile doğum ağırlığının azalmasıyla birlikte artmaktadır. SP için en sık tanımlanan prenatal risk faktörleri prematürite ve/veya düşük doğum ağırlığıdır. SP'ye neden olan zedelenme progresif olmamakla birlikte, klinik tablo beyin olgunlaştıkça zamanla değişebilir. Bu yazıda, SP'nin epidemiyolojisi, etiyolojisi ve patolojisi gözden geçirilmiştir.
\end{abstract}

Anahtar sözcülkler: serebral palsi; epidemiyoloji; etiyoloji; patoloji
Cerebral palsy is a heterogeneous group of clinical syndromes that range in severity, and characterized by abnormal muscle tone, posture, and movement. These conditions are due to abnormalities of the developing brain resulting from a variety of causes. The overall prevalence of cerebral palsy is approximately 2 per 1000 live births. The prevalence of cerebral palsy is far higher in preterm compared with term infants, and increases with decreasing gestational age and birth weight. Most commonly identified prenatal risk factors for cerebral palsy are prematurity and/or low birth weight. Although the disorder itself is not progressive, the clinical expression may change over time as the brain matures. In this paper, the epidemiology, etiology, and pathology of cerebral palsy are reviewed.

Key words: cerebral palsy; epidemiology; etiology; pathology erebral palsi (SP), prenatal, perinatal veya erken postnatal dönemden kaynaklanan ve ağırlıklı olarak motor belirtilerle seyreden, çeşitli klinik tabloları kapsayan bir "şemsiye tanım"dır. Bulgular, çocuğun büyüme ve gelişim sürecinde değişmekle beraber, ilerleyici olmayan, hareket kısıtlayı$\mathrm{Cl}$, anormal kas tonusu, postür ve hareket bozukluğu ile karakterize bir hastalıktır. SP tanısı, etiyolojik bir tanı olmayıp klinik değerlendirmeye dayalı bir durumu yansitır. ${ }^{[1]}$

\section{EPIDEMIYOLOJi}

SP'nin sıklığı ortalama her 1000 canlı doğumda 2 olarak bildirilmektedir. Sıklık, preterm infantlarda daha yüksek olup, gestasyonel yaş ve doğum ağırlığının azalmasıyla birlikte artış göstermektedir (Tablo 1). ${ }^{[2-4]}$

\section{ETIYOLOJi}

SP etiyolojisinde, doğum öncesi, doğum ve doğum sonrasına ait birden fazla risk faktörü bulunmaktadır. Etiyolojide \%70-80 doğum öncesine ait patolojiler rol oynar ve en sık saptanan neden erken doğumdur. Prematüritelerde görülen intraventriküler kanama, periventriküler lökomalazi ve bronkopulmoner displazi, SP gelişimi ile sıklıkla ilişkilidir. İntrauterin büyüme geriliği, intrauterin enfeksiyonlar, antepartum kanama, ağır plasenta patolojileri ve çoğul gebelikler de ilişkili diğer sık görülen nedenlerdir. Perinatal hipoksik-iskemik hasarlanma en sık şüphe edilen neden olmasına rağmen, olguların küçük bir kısmından sorumludur. Olguların \%10-20'sinde ise etiyolojik neden gösterilemez (Tablo 2). ${ }^{[2-5]}$

SP, benzer lokalizasyonda ve benzer beyin hasarları sonucu meydana gelmiş olmasına rağmen klinik

- İletişim adresi: Doç. Dr. Yasemin Topçu, Medipol Üniversitesi Tıp Fakültesi, Çocuk Nörolojisi Bilim Dalı, İstanbul Tel: 0505 - 4934070 e-posta: drytopcu@yahoo.co.uk

- Geliș tarihi: 1 Ekim $2018 \quad$ Kabul tarihi: 1 Ekim 2018 
etkileri değişkenlik göstermektedir. Bu değişkenliğin nedeni SP'nin çok etkenli bir hastalık olmasıdır. ${ }^{[6]}$ SP etiyolojisinde, preterm doğum ve intrauterin büyümegelişme geriliği gibi klinik risk faktörleri iyi tanımlanmış olmasına rağmen, genetik ilişkiler ile ilgili bilgiler son yıllarda ortaya çıkmaya başlamıştır. ${ }^{[7]}$ Günümüzde, genlerdeki polimorfik değişikliklerin klinik etkilerin değişkenliği üzerine etkisini gösteren çalışma sayısı giderek artmaktadır. ${ }^{[6]}$ Bu çalışmalarda elde edilen sonuçlara göre, genetik polimorfizmler bireyin SP duyarlılığı için değişken etkiler göstermektedir. Apolipoprotein $E$, interlökin-6, interlökin-8, tümör nekroz faktör- $\alpha$, indüklenebilir nitrik oksit sentaz (i-NOS), lenfotoksin 60 , Faktör $V$ Leiden, metilentetrahidrofolat redüktaz (MTHFR), protrombin ve platellet aktivatör inhibitör genlerindeki polimorfizmler en çok araştırılan genetik polimorfizmlerdir. ${ }^{[8]}$

\section{PATOLOJi}

SP, beyin korteksindeki üst motor nöronların zedelenmesi sonucu gelişir. Üst motor nöronlar istemli

Tablo 1. Serebral palsi sıklığ| ${ }^{[2-4]}$

Gestasyonel yaş:

- Gestasyonel yaş <28 hafta: 1000 canlı doğumda 82

- Gestasyonel yaş 28-31 hafta: 1000 canlı doğumda 43

- Gestasyonel yaş 32-36 hafta: 1000 canlı doğumda 6,8

- Gestasyonel yaş >36 hafta: 1000 canlı doğumda 1,4

Doğum ağırlığı:

- <1500 gr: 1000 canlı doğumda 59,2

-1500-2499 gr: 1000 canlı doğumda 10,2

- >2500 gr: 1000 canlı doğumda 1,33 hareketi başlattığı gibi spinal ön boynuzundaki alt motor nöron işlevlerini baskılama görevini de yapar. Zedelenme sonucu üst motor nöronların baskılayıcı görevleri azalır. Korteksten, kortikospinal ve retikülospinal yollarla gelen uyarılar azalarak kas kontrolü bozulur ve kas tonusu artar. SP'de üst motor nöron işlevleri beyin gelişimi sırasında toksik, enfeksiyöz ve vasküler yetersizlik sonucu bozulur. Böylece beyinde anormal gelişme süreci başlar. Embriyolojik dönemde beynin farklı bölgelerinin yapıları nedeniyle zedelenmenin tipi ve derecesi beynin gelişim evrelerine göre şekillenir. Beyindeki iskemi, intrauterin 20. haftadan önce olmuş ise migrasyon anomalileri; 26.-34. haftalarda olmuş ise periventriküler lökomalazi, gebeliğin geç dönemlerinde oluşmuş ise kortikal ve derin gri cevherde fokal veya multifokal serebral zedelenmeler, bazal ganglia, talamus lezyonları, orta serebral arter infarktı şeklinde görülür. Klinik bulgular lezyonun tipine, oluştuğu zamana, bulunduğu bölge ve genişliğine, sinir siteminin zedelenmeye karşı gösterdiği uyum yeteneğine göre değişir. Beynin uyum yeteneği, gelişimin ilk haftalarında en fazladır ve hamileliğin sonuna doğru azalır. Beyindeki küçük lezyonlarda işlevsel geri dönüş daha kolay iken büyük lezyonlarda kortikospinal yollarla karşı beyin hemisferi yeni duruma uyum sağlar. Prematüritelik, serebral vaskülaritenin olgunlaşmamış olması nedeniyle, beyin kan akımında farklılıklara ve SP riskinin artmasına neden olur. ${ }^{[9]}$

- Parasagittal Beyin Zedelenmesi: Term bebeklerde gözlenen başlıca lezyondur ve genellikle perinatal asfiksi ile beraber görülür. ${ }^{[10]}$ Miyadında doğan bebeklerde beyin kan akımının azalması, kortikal ve subkortikal beyaz cevherdeki büyük damarların sulama alanlarının kesişme noktalarında nekroza neden olur. ${ }^{[11]} \mathrm{Bu}$ bölgeler kan akımındaki

Tablo 2. Serebral Palsi için risk faktörleri ${ }^{[2-5]}$

\begin{tabular}{lll}
\hline Doğum öncesi & Doğum süreci & Doğum sonrası \\
\hline • Intrauterin enfeksiyonlar & $\bullet$ Prematürite & $\bullet$ Hipoksik iskemik ensefalopati \\
- Kanama & $\bullet$ Düşük doğum ağırlığı & $\bullet$ İntrakraniyal kanama \\
- Servikal yetmezlik & $\bullet$ Plasenta previa & $\bullet$ Polisitemi \\
$\bullet$ Çoğul gebelikler & $\bullet$ Ablasyo plasenta & $\bullet$ Santral sinir sistemi enfeksiyonu \\
• Serebral disgenezis & $\bullet$ Plasenta infarktı & $\bullet$ Hipoglisemi \\
- Plasenta anomalileri & $\bullet$ Koryoamniyonit & $\bullet$ Koagülopati \\
- Tromboz & $\bullet$ Erken mebran yırtığı & $\bullet$ Hiperbilirubinemi \\
- Gebelik toksemisi & $\bullet$ Anormal prezentasyon & $\bullet$ Tekrarlayan konvülziyonlar \\
- Annenin kronik hastalıkları & $\bullet$ Düşük apgar skoru &
\end{tabular}


düşmelere çok duyarlıdır. Özellikle perinatal asfiksi sırasında gelişen sistemik tansiyon düşüklüğü ve ardından gelen beyin dolaşımının otoregülasyonunun bozulmasına bağlı gelişmektedir. ${ }^{[12,13]}$

- Periventriküler Lökomalazi: Prematürelerde fetal beyin dolaşımı, periventriküler beyaz cevherde perfüzyon azalmasına neden olur. Lateral ventriküle komşu germinal matriks kılcal damarları, striat ve talamik arterlerin sonlandığı vasküler sınırda olduğu için iskemik zedelenmeye çok duyarlıdır. Bu bölgedeki beyaz cevherden, alt ekstremitelerin motor kontrol ve kas tonusundan sorumlu lifler geçmektedir. Bu nedenle, klinik olarak spastik dipleji gelişir. ${ }^{[14]}$

- Fokal ve Multifokal Beyin Nekrozu: En fazla etkilenen bölgeler, orta serebral arter sulama alanlarıdır. Erken gestasyonel nekrozlara bağlı prozensefali, multikistik ensefalomalazi ve hidranensefali gelişebilir. ${ }^{[14]}$

- Status marmoratus: Miyadında doğanlarda, hipoksik iskemik ensefalopatiye bağlı olarak nadiren gelişir. Bazal gangliyonlarda patolojik olarak mermer görünümü, nöron kaybı, gliozis ve hipermiyelinizasyon görülür. ${ }^{[14]}$

- Selektif Nöron Nekrozu: Hipoksik iskemik zedelenmede en çok görülen zedelenme tipidir. Mental retardasyon ve konvülziyonla kendini gösterir. ${ }^{[15]}$

\section{KAYNAKLAR}

1. Panteliadis CP. Serebral Palsi, Multidisipliner Yaklaşım. Günel MK, Anlar B, çev. editörleri. Pelikan Kitabevi; 2015.

2. Platt MJ, Cans C, Johnson A, Surman G, Topp M, Torrioli MG, Krageloh-Mann I. Trends in cerebral palsy among infants of very low birthweight $(<1500 \mathrm{~g})$ or born prematurely (<32 weeks) in 16 European centres: a database study. Lancet 2007;369(9555):43-50. Crossref

3. Andersen GL, Romundstad P, De La Cruz J, Himmelmann K, Sellier E, Cans C, Kurinczuk JJ, Vik T. Cerebral palsy among children born moderately preterm or at moderately low birthweight between 1980 and 1998: a European registerbased study. Dev Med Child Neurol 2011;53(10):913-9. Crossref
4. Sellier E, Platt MJ, Andersen GL, Krageloh-Mann I, De La Cruz J, Cans C. Decreasing prevalence in cerebral palsy: a multi-site European population-based study, 1980 to 2003. Dev Med Child Neurol 2016;58(1):85-92. Crossref

5. Shevell MI. The "Bermuda triangle" of neonatal neurology: Cerebral palsy, neonatal encephalopathy, and intrapartum asphyxia. Semin Pediatr Neurol 2004;11(1):24-30. Crossref

6. Blackman JA, Gurka MJ, Bao Y, Dragulev BP, Chen WM, Romness MJ. Apolipoprotein E and functional motor severity in cerebral palsy. J Pediatr Rehabil Med 2009;2(1):67-74. Crossref

7. O'Callaghan ME, MacLennan AH, Gibson CS, McMichael GL, Haan EA, Broadbent JL, Goldwater PN, Painter JN, Montgomery GW, Dekker GA, for the Australian Collaborative Cerebral Palsy Research Group. Fetal and maternal candidate single nucleotide polymorphism associations with cerebral palsy: A case-control study. Pediatrics 2012;129(2):e414-23. Crossref

8. Wu YW, Croen LA, Vanderwef A, Gelfand AA, Torres AR. Candidate genes and risk for CP. A population-based study. Pediatr Res 2011;70(6):642-6. Crossref

9. Swaiman K, Wu Y. Cerebral palsy. In: Swaiman K, Ashwal $S$, Ferriero DM, editors. Pediatric Neurology: Principles and Practice. 4th ed. Philadelphia: Mosby Elsevier Comp; 2006. p.491-504.

10. Volpe JJ, Hill A. Hypoxic-ischemic cerebral injury in the newborn. In: Swaiman KF, Ashwal S, editors. Pediatric Neurology: Principles \& Practice, 3rd ed. St Louis: Mosby; 1999. p.204-191.

11. Volpe JJ. Neurology of the newborn, Chapter 13. Bilirubin and Brain Injury, 5th ed. Philadelphia, PA: WB Saunders Company; 2008. p.619-51.

12. Volpe JJ. Value of MR in definition of the neuropathology of cerebral palsy in vivo. AJNR Am J Neuroradiol 1992;13(1):79-83.

13. Groenendal F, van der Grond J, Eken P, van Haastert IC, Rademaker KJ, Toet MC, de Vries LS. Early cerebral proton MRS and neurodevelopmental outcome in infants with cystic leukomalacia. Dev Med Child Neurol 1997;39(6):373-9.

14. Volpe JJ. Neurology of the newborn, 3rd ed. Philadelphia: WB Saunders Comp; 1995. p.403-463.

15. Volpe JJ. Neurology of the newborn. Chapter 8. Hypoxicischemic encephalopathy: neuropathology and pathogenesis, 5th ed. Philadelphia: WB Saunders Company; 2008. p.347-99. 